\title{
The Impact of Industrial Structure on Economic Growth in Baoshan, Yunnan Province
}

\author{
Meijuan Li \\ School of Economics and Management \\ Yunnan Normal University \\ Kunming 650092, China
}

\author{
Qiufang Huang \\ School of Economics and Management \\ Yunnan Normal University \\ Kunming 650092, China
}

\begin{abstract}
To promote the industrial structure more reasonable, and enhance the economic growth rate in Baoshan, which is located in the west of Yunnan province, we establish econometric model to analyze the impact of Baoshan's industrial structure on its economic growth. Our results show that the three industries in Baoshan have a significant positive correlation with GDP, and their marginal contributions to economic growth are different. The third industry in Baoshan has the greatest contribution to economic growth, its contribution elasticity is 0.448406; followed the first industry, its contribution elasticity is 0.408176; finally the second industry, Which has the least elasticity of contribution to economic growth, only 0.186153 , According to the research conclusion, the countermeas-ures of three industrial development are put forward to promote the fast and good growth of Baoshan economy.
\end{abstract}

Keywords-Industrial Structure; Economic Growth; Empirical Analysis; Baoshan

\section{INTRODUCTION}

In recent years, in the implementation of the"the Belt and Road" and "bridgehead" initiative, Yunnan's economy has substantially grown [1]. However, the regional economic gap and bottleneck constraints still exist. With the advent of the information age, the trend of economic globalization has been deepening. The new economic factors, which are centered on technological innovation, top talents and low carbon environmental protection, have begun to permeate all fields of the economy and society. This has a new impact on the development of industries and the inter-industry relations, and gradually forms a new impetus to promote the adjustment and evolution of the world's industrial structure. Baoshan which locates in the west of Yunnan is the political, economic and cultural center of Western Yunnan. It is an important trading hub in Yunnan province [2]. As national policies move to the West, Baoshan's economic growth is fast. In 2016, GDP has achieved 55.195 billion yuan, accounting for $4 \%$ of the total value of GDP in Yunnan province. We examine the present situation of industrial structure and use econometric model to analyze the marginal contribution of the three industries to their economic growth in Baoshan.Combined with the location, resources and economic development of Baoshan, this paper puts forward some suggestions to promote the optimization of industrial structure and economic growth according to local conditions, so as to bring about the development of the surrounding areas of Baoshan.

\section{THE PRESENT SITUATION OF INDUSTRIAL STRUCTURE IN BAOSHAN}

Since the reform and opening up, the government of Baoshan has been adjusting its industrial structure and changing the mode of economic development, so this area has been experiencing the rapid economic growth. The proportion of all industries has been constantly adjusted, the proportion of the first industry is decreasing while the second industry is increasing year by year, the third industry keeps steady. In 2016 , the ratio between industries is $25.7: 34.8: 39.5$.We can see that, the third industry, which bases on tourism, has the highest proportion. In the following sections, we will illustrate the current situation of industrial structure in Baoshan from three aspects by selecting the three industrial output value, the three industry composition and the three industry internal structure output value data in 2001-2015.

\section{A. Output value of the Three Industries}

In 2015, Baoshan's gross domestic product (GDP) achieved 55.196 billion Yuan, of which the output values of the three industries were 14.197 billion yuan, 19.205 billion yuan and 21.793 billion yuan respectively. In 2010-2015, the output values of the three industries in Baoshan had increased year by year, and the output value of the third industry had been the highest. In 2001, the output values of the first and third industries were very close, but the growth rate of the first industry was lower than that of the second industry .Since 2010 , the output value of the first industry has been lower than that of the second industry, and the output value of the second industry, which is mainly based on industry and construction, has been increasing rapidly.

\section{B. Composition of the three industries}

Through the continuous efforts of the government, the proportion of the three industries in Baoshan changed from 40.2:19.8:40 in 2001 to 25.7:34.8:39.5 in 2015 (Table 1). The third industry had the highest proportion, the proportion of the second industry was increasing year by year, and the proportion of the first industry was declining. The industrial structure of Baoshan has become more and more reasonable with the adjustment of policies and the development of economy. The industrial structure has gradually shifted from the" 312 " model to the" 321 " model. But the primary industry still occupies a higher proportion. 
TABLE I. THE STRUCTURE RATIO OF THE THREE INDUSTRIES IN BAOSHAN(2001-2015)

\begin{tabular}{|c|c|c|c|}
\hline \multirow{2}{*}{ year } & \multicolumn{3}{|c|}{ Structure of the three industries (\%) } \\
\cline { 2 - 4 } & The first industry & The second industry & The third industry \\
\hline 2001 & 40.2 & 19.8 & 40 \\
\hline 2002 & 38.9 & 19.6 & 41.5 \\
\hline 2003 & 37.2 & 20.3 & 42.5 \\
\hline 2004 & 35.8 & 21.8 & 42.4 \\
\hline 2005 & 36 & 24.5 & 39.5 \\
\hline 2006 & 33.8 & 26.6 & 39.6 \\
\hline 2007 & 32.29 & 28.05 & 39.66 \\
\hline 2008 & 31.8 & 28.5 & 39.7 \\
\hline 2009 & 32.6 & 28.6 & 38.8 \\
\hline 2010 & 30.28 & 30.87 & 36.85 \\
\hline 2011 & 31.02 & 32.11 & 36.70 \\
\hline 2012 & 28.96 & 34.34 & 36.90 \\
\hline 2013 & 28.58 & 34.52 & 38.3 \\
\hline 2014 & 27.1 & 34.6 & 39.5 \\
\hline 2015 & 25.7 & 34.8 & \\
\hline
\end{tabular}

\section{Internal structure of the three industries}

The first industry in Baoshan are mainly walnut, rape, coffee, sugar cane, tobacco and other agricultural cultivation. The second industry has a weak industrial foundation and has not formed an industrial chain.it has not yet formed scale until now. The third industry is mainly based on tourism, and has a large proportion in the industrial structure.

\section{1) Internal structure of the first industry}

In 2015, the added value of the first industry in Baoshan was 14.197 billion yuan, up $4.3 \%$ over 2014 . The total output of grain was about 1.43 million tons, and the per capita possession of grain is the first in Yunnan Province. Livestock output value was 9.8 billion yuan, up $8.7 \%$ over 2014.Tobacco, animal husbandry, walnut, dendrobium, tea, sericulture, coffee, Chinese herbal medicine, edible fungi, waxy olives, camellia chekiang-oleosa and other characteristic industry have developed steadily, which have made full use of the basic role of agriculture.

In 2001-2014, the output value of the first industry in Baoshan increased from 3.052 billion yuan to 13.611 billion yuan. The added value of agriculture, forestry, animal husbandry and fishery all increased in different degrees, but the growth of agriculture was greater than the other, and the growth of animal husbandry was second. In 2010, forestry output fell sharply. It may be that the forest fire caused by the source of fire from overseas in February 2009 resulted in the decline of the output of forestry in Tengchong county, Baoshan city. Meanwhile, so it was in the Longyang district,
Baoshan city, a forestry centre broke out of fire led to the loss of which over 400 acres of forest had been fired in December 2010. But in the government's policy of silviculture, the output value of forestry has been increasing. Fishery output remained stable, but the proportion of forestry and fishery is low. The internal structure doesn't correspond and the overall advantage is not obvious.

\section{2) Internal structure of the second industry}

With the constant adjustment and efforts of the county governments, the industry and construction industry of Baoshan have been developing continuously, and the output value of the second industry has been increasing yearly. In 2015, the output value of Baoshan's second industry was 19.205 billion yuan, up to $34.8 \%$. The added values of Baoshan's industry and construction industry are increasing year by year. At present, the industry of Baoshan occupies a large proportion in the second industry, achieving $71 \%$ in 2015.But the supporting facilities of the industrial parks are not complete, production lines and industrial parks are just planning to start, so it does not formed the industrial chain.

Although the light industry of tobacco in Baoshan has developed rapidly in recent years, some villages which mainly focus on electric power, building materials and silicon smelting in Baoshan, some villages in Tengchong such as DianTan, MingGuang which primarily engage in non-ferrous metal metallurgy that include lead ore products, iron ore, zinc ore products, have industrial parks. In these areas, the majority of industrial sectors rely on resources and they don't have the power of efficient development. At the same time, they are 
vulnerable to weather and technology. To solve this problem, we also need to introduce leading enterprises with high and new technology advantages to promote the intensive processing of mineral products and jade products.Furthermore,leading enterprises should guide local enterprises to strengthen technological innovation, and gradually eliminate backward industries with high energy consumption and high pollution under the efforts and cooperation of all levels of society.

\section{3) Internal structure of the third industry}

With the increase of per capita income and consumption demand, the third industry, which is mainly service oriented, has been developed. Finance and insurance have been better developed as well. In 2015, the balance of RMB deposits of financial institutions in Baoshan was 77.503 billion yuan, the insurance company's premium income is 1.565 billion Yuan. More attention has been paid to education, with the result that the enrolment rate has been further improved. In addition, the urban tourism, which is based on Tengchong, has developed rapidly.

In recent years, Baoshan gives priority to tourism and focuses on the development of Tengchong which is built as a tourist city, taking "healthy tourism" as the theme to form an image of jewelry, hot springs, and leisure. At the same time, Tengchong will be built into "sunshine outdoor sports paradise". Baoshan will strive to build the volcanic region in the Mazhan village and cloud mountain in Diantan town into a worldwide recreational base for outdoor sports. And optimize ecological and natural scenic spots of the Silk Road in Gaoligong Mountain. In 2015, the total number of tourists in Baoshan reached 1279.38 million people, increased 5.2 times than 2001, and the total tourism revenue achieved 11.279 billion yuan, increased 19.32 times than 2001, promoting the vitality of the development of the third industry.

\section{AN EMPIRICAL ANALYSIS OF THE INFLUENCE OF INDUSTRIAL STRUCTURE ON ECONOMIC GROWTH IN BAOSHAN}

\section{A. The Model}

When analyzing the influence of the three industries on economic growth in China, Liu Wei and Li Shaorong (2002) use the model $Y=f(X 1, X 2, X 3, A)$ to measure and calculatethe contribution of the three industries to economic growth [3].The endogenous variable of the model is the first, second, third industrial output value, while the economic system and technological level are exogenous variables. In the model, Y represents the gross domestic product (GDP), and $\mathrm{X}_{\mathrm{i}}$ represents the output value of the industry $i(i=1,2,3)$.Lastly, A represents the technical level and the economic system. Under the influence of economic system, some industries have higher collinearity, or some industries don' t contribute significantly to total output, but together with other industries, it has a great impact [4]. We consider this industries as part of the economic system, not the industrial sector. Therefore, in the national economic accounting, there is a possibility that the total output is not equal to the sum of all industrial output. The econometric model for calculating the marginal contribution of Baoshan's industrial structure to economic growth is set as follows:

$$
\text { Lny }=\beta_{0}+\beta_{1} \ln x_{1}+\beta_{2} \ln x_{2}+\beta_{3} \ln x_{3}+A
$$

\section{B. Data sources}

The datas used in this paper are derived from "statistical yearbook of Yunnan Province "and the "statistical bulletin on national economic and social development of Baoshan"in 2001-2016.

\section{Empirical test}

\section{1) The stationarity test of time series}

The datas used in this paper are in the form of time series, but the datas for most time series are non-stationary. If the datas are directly regression analysis, spurious regression problems may occur. It means that there is no meaningful linear relationship between variables, but the regression results are very significant, which leads to erroneous conclusions that have significant relations. Therefore, before doing regression analysis, it is necessary to verify the stationarity of data, and the method of verification is ADF unit root test [5].

Figure 1 shows a clear linear relationship between variables. The natural logarithm of the data not only does not affect the causal relationship between original variables, but also can make the trend more linear. It can eliminate the possible heteroscedasticity in the time series and make the regression result more credible and scientific [6].

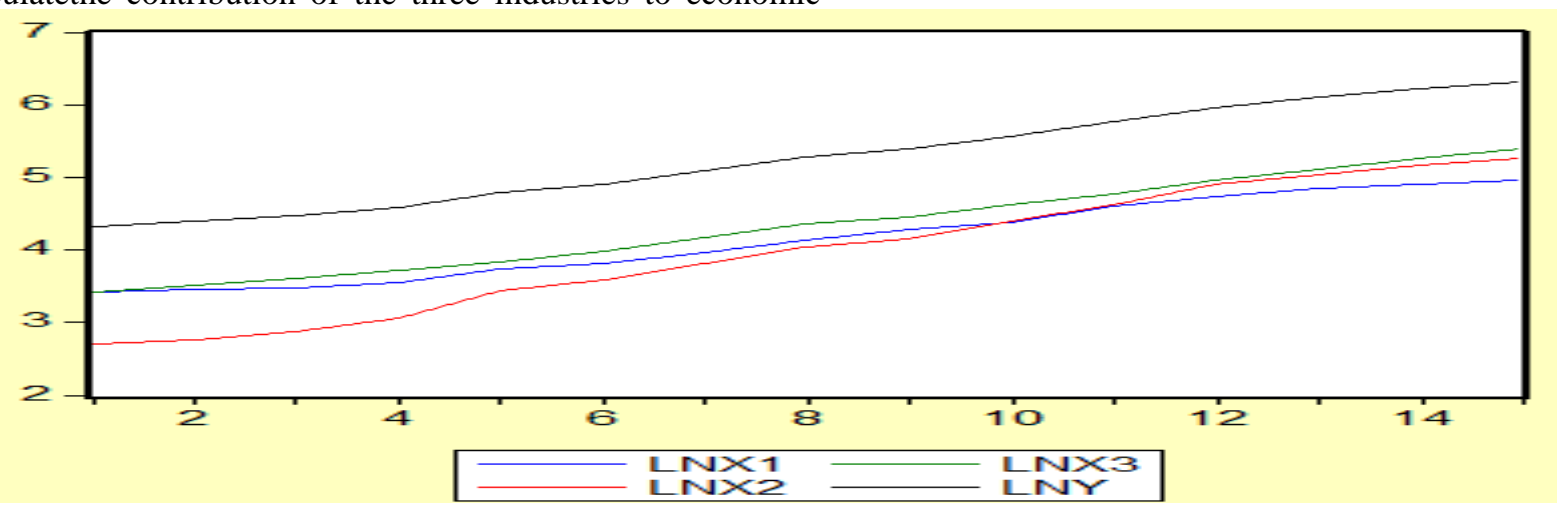

Fig. 1. A trend chart of $\ln y, \ln x_{1}, \ln x_{2}$, and $\ln x_{3}$ made by Eviews 3.1 
The unit root test is used to test the stability of four variables, $\ln y, \ln x_{1}, \ln x_{2}$ and $\ln x_{3}$, and the results are shown in table 2:

TABLE II. ADF TEST RESULTS OF GDP AND THREE INDUSTRY SEQUENCES

\begin{tabular}{|c|c|c|c|c|}
\hline variable & Test form & $\begin{array}{c}\text { ADF statistical } \\
\text { value }\end{array}$ & $\begin{array}{c}\text { Critical value } \\
(10 \%)\end{array}$ & $\begin{array}{c}\text { Stationary } \\
\text { or non-stationary }\end{array}$ \\
\hline Lny & $(\mathrm{C}, \mathrm{N}, 0)$ & 0.628981 & -2.6972 & non-stationary \\
\hline $\ln \mathrm{x}_{1}$ & $(\mathrm{C}, \mathrm{N}, 0)$ & 0.274452 & -2.6927 & non-stationary \\
\hline $\ln \mathrm{x}_{2}$ & $(\mathrm{C}, \mathrm{N}, 1)$ & -2.523218 & -3.3588 & non-stationary \\
\hline $\ln \mathrm{x}_{3}$ & $(\mathrm{C}, \mathrm{N}, 0)$ & 1.382825 & -2.6927 & non-stationary \\
\hline$\Delta \ln \mathrm{y}$ & $(\mathrm{C}, \mathrm{T}, 1)$ & -2.737381 & -2.7180 & stationary \\
\hline$\Delta \ln _{1}$ & $(\mathrm{C}, \mathrm{T}, 0)$ & -2.758698 & -2.7042 & stationary \\
\hline$\Delta \ln _{2}$ & $(\mathrm{C}, \mathrm{T}, 0)$ & -3.085259 & -2.7042 & stationary \\
\hline$\Delta \ln _{3}$ & $(\mathrm{C}, \mathrm{T}, 0)$ & -2.812603 & -2.7042 & stationary \\
\hline
\end{tabular}

The table 3 shows that the four variables are non-stationary sequence in the original level, but it is a stationary sequence at the critical value of $10 \%$ by the first order difference, which means that four variables are integrated of order1, that is, their linear combination is stationary.

\section{2) Regression analysis}

According to the sample observation of Baoshan's GDP, the first industry, the second industry and the third industry in 2001 to 2015,regression analysis is carried out by Eviews3.1, and the following regression equation is obtained:

Lny $=0.894041+0.408176 \operatorname{lnx}_{1}+0.186153 \operatorname{lnx}_{2}+$ $0.448406 \ln x_{3}$

$$
\begin{array}{cccc}
\mathrm{t}= & \begin{array}{llll}
(21.04143) & (14.0315) & (10.8968) & (19.1634)
\end{array} \\
\mathrm{R}^{2}=0.9999 & \mathrm{~F}=107284.1 \quad \mathrm{n}=15 &
\end{array}
$$

\section{a) Cointegration test}

Cointegration means that some linear combination of multiple non-economic variables is stationary. In this paper, we mainly perform the ADF test on the residual sequence, that is, we perform unit root test on "et" to test the stationarity of "et".If the "et" is stationary, then the four sequence is cointegration relation, which means that there is a long-term stable relationship between the sequences but not vice versa[7] The table 3 is the result of the cointegration test:

TABLE III. TEST RESULTS OF RESIDUAL SEQUENCE “ET"

\begin{tabular}{|c|c|c|c|c|}
\hline variable & Test form & $\begin{array}{c}\text { ADF statistical } \\
\text { value }\end{array}$ & $\begin{array}{c}\text { Critical value } \\
(10 \%)\end{array}$ & $\begin{array}{c}\text { Stationary or non- } \\
\text { stationary }\end{array}$ \\
\hline et & $(0,0,0)$ & -2.787240 & -2.6927 & Stationary \\
\hline
\end{tabular}

As can be seen from the table 3 , the ADF statistic value is significantly lower than the critical value. According to the test criterion, the "et" has no unit root, and the sequence is cointegration at the significance level. That is to say, for Baoshan, the three industries have long-term balanced relation to economic growth, which means that the three industries have contributed to economic growth, and the adjustment of the three industrial structure plays a catalytic role in economic growth.

\section{b) Fit goodness test}

In the linear regression model, $\mathrm{R}^{2}$ is the coefficient of determination, which is used to represent the fitting degree of the model estimated by the multiple linear regression equation to the sample observations. The greater the $\mathrm{R}^{2}$, the higher the degree of interpretation of the explanatory variables to the explained variables, the more significant the regression model. In the regression equation, $\mathrm{R}^{2}=0.9999$, and the modified coefficient of determination is 0.999957 , indicating that model is well fitted.

\section{c) F test}

The $\mathrm{F}$ test is the significance test which represents the conceptual data, and F statistic obeies the degree of freedom, respectively, $\mathrm{F}$ distribution of $\mathrm{k}-1$ and $\mathrm{n}-\mathrm{k}$.The principle is: at the confidence level of $\alpha$, the critical value $F_{\alpha}(k-1, n-k)$ can be found in the $\mathrm{F}$ distribution table, if the $\mathrm{F}>\mathrm{F}_{\alpha}(\mathrm{k}-1, \mathrm{n}-\mathrm{k})$, the regression equation is significant but not vice versa. When $\alpha=0.05$, the critical value $F_{\alpha}(3,11)=3.863$.In regression equation, $F=107284.1$.It is larger than $F_{\alpha}(3,11)=3.863$, which means that this equation is significant.

\section{d) T test}

The analysis of multiple linear regression model, on the one hand, is to make a model with higher goodness of fit, on the other hand, it is to make the estimation of regression parameters meaningful. Therefore, the overall linear relation of the regression equation may be significant, but the influence of each explanatory variable is not significant. This requires further significance tests on explanatory variables [8]. The principle is that if the $|\mathrm{t}|>=\mathrm{t}_{\alpha / 2}(\mathrm{n}-\mathrm{k})$, in other words, $\mathrm{t}<=-$ $\mathrm{t}_{\alpha / 2}(\mathrm{n}-\mathrm{k})$ or $\mathrm{t}>=\mathrm{t}_{\alpha / 2}(\mathrm{n}-\mathrm{k})$, It shows that the explanatory variable 
$\mathrm{X}_{\mathrm{j}}$ has significant influence on the explained variable $\mathrm{Y}$ when other explanatory variables remain unchanged, Conversely, if $|\mathrm{t}|<\mathrm{t}_{\alpha / 2}(\mathrm{n}-\mathrm{k})$, that is, $-\mathrm{t}_{\alpha / 2}(\mathrm{n}-\mathrm{k})<\mathrm{t}<\mathrm{t}_{\alpha / 2}(\mathrm{n}-\mathrm{k})$, it indicates that, in the case of other explanatory variables unchanged, the explanatory variable $X_{j}$ has no significant effect on the explained variable Y.At significant level $\alpha=0.05$, The degree of freedom is that $n-k=11$, and the critical value is that $t_{0.025}(n-k)$ $=2.201$.In the regression equation, the $\mathrm{t}$ statistics corresponding to $\beta_{1}, \beta_{2}$ and $\beta_{3}$ are $14.0315,10.8968$ and 19.1634 respectively. The absolute values are greater than $\mathrm{t}_{0.025}(\mathrm{n}-\mathrm{k})$ which is 2.201 , so the t-test passes, and the three explanatory variables have significant effects on the explained variables.

\section{CONCLUSIONS AND RECOMMENDATIONS}

\section{A. Conclusions}

From the regression analysis above, we can draw the conclusion that the three industries of Baoshan have a significant positive correlation with GDP, and their marginal contributions to economic growth are different. The contribution elasticity of the third industry in Baoshan is 0.448406 ,it is to say, with the proportion of the third industry increasing by $1 \%, \mathrm{GDP}$ will increase by $0.448406 \%$.Similarly, the contribution elasticity of the first industry is 0.408176 ,it means that the proportion of the first industry increased by $1 \%$, GDP will increase by $0.408176 \%$.But the second industry has the least elasticity of contribution to economic growth, only 0.186153 , that is, the proportion of the second industry increased by 1\%, GDP will increase by $0.186153 \%$. Therefore, the third industry has the highest degree of contribution to the economic growth, followed the first industry, finally the second industry.

\section{B. Recommendations}

1) Optimize the structure of agricultural planting reasonably,promote the modernization of Agriculture

Baoshan has a large rural population, and the majority of them are mainly in the first industry [9], which contributes more to the economic growth. Therefore, it is necessary to adjust and optimize the agricultural structure according to local conditions, to make the first industry play a more efficient basic role and promote the output value of the second and the third industry with high efficiency agricultural development. Located in the Yunnan-Guizhou Plateau, Bashan is a subtropical humid monsoon climate, which is characterized by abundant rain and sunshine all the year round, no severe cold in winter and no hot in summer. It is a good place for agricultural cultivation. Because of its own climatic characteristics, Baoshan can focus on the development of six major industries: tea, grain, rape, tobacco, animal husbandry and economic forest. But the output value of animal husbandry in Baoshan is relatively low, so it is necessary to improve the technical level, especially the service system of animal husbandry, strengthen the epidemic prevention system and promote the development of productivity. Baoshan city consists of four regions, and each region can develop its characteristic industry according to its own characteristics. Such as Tengchong's oolong tea, Changning's juglans sigillata and Shidian's letinous edodes.Enterprises should strengthen the road of sustainable development, improve the quality of agricultural products, enhance competitiveness, make agriculture green and ecological, and realize the modernization of agriculture.

2) Foster and develop new technological industries, enhance the competitiveness of industrial output

The second industry in Baoshan has the minimum contribution to economic growth, in which, the industry occupies a significant proportion, and the industrial structure is backward. On the one hand, the traditional industry which depends on resource shows the character of "three high", namely high pollution, high energy consumption, high cost; on the other hand, a large number of enterprises are still in the stage of primitive accumulation, and few companies can rely on their own. The industrial products produced by these enterprises have high substitutability, low added value and lack of competitive advantage. Therefore, they need strong support of the government.

a) Eliminate and restructure the three high industries,raise the industrial level

Baoshan has rich mineral resources. Firstly, we needs to eliminate the industries with high pollution, high energy and low production value based geographical and resource advantages. Secondly, Baoshan needs to make a deep process of basalt fiber, diatomite and lava, and cultivate jade and jade processing industry. Thirdly, it should strengthen the intensive processing of special agricultural products, such as oil, tea, and Xinzhai coffee. In addition, Further to develop bio pharmaceutical, ecological preserved fruit processing industry.Finally,we should support the development of Tengyao company, provide funds and policy support for emerging enterprises, speed up industry cultivation, expand industrial scale effects, adjust the proportion of light and heavy industries, raise industrial levels and speed up economic growth.

b) Speed up the construction of the "park in the park ", promote the development of industrial agglomeration

In recent years, Baoshan has planned and built five provincial-level industrial parks, which have promoted economic development. However, there are still some problems, such as poor facilities supporting capacity, inchoate industrial chain, low quality and low efficiency. In order to solve these problems, municipal government in Baoshan has proposed to accelerate the construction of the "park in the park ", and realize the park development in five counties. Measures are as follows:Firstly,it is better to plan for the construction of industrial parks on the aspects of the electronic information in Longyang district, the biological resources processing in Changning county, the equipment manufacturing in Shidian county and silica-based support in longling county ect.Secondly, the development of the industrial agglomeration with the local feature of "Baoshan pattern"should be built rapidly.Thirdly,relevant departments must attract investment in accordance with strict policies and measures, so as to strengthen supporting capacity and reduce costs. At the same time, Government should appropriate funds and provide security for financial, job and policy etc. Optimize the layout 
of industrial networks, improve the planning of processing and trading enterprises, and accelerate the development of ecommerce and the expansion of trade logistics bases.

3) Fully exert the advantages of resources and location, vigorously develop the tourism service industry

In the three industry of Baoshan, the third industry has the most marginal contribution to the economic growth, but the growth rate of the third industry is relatively slow, and the development of the third industry should be greatly strengthened. With abundant geothermal resources and unique climatic conditions, Baoshan has formed a unique hot spring entertainment and recreation area and a large number of tourist attractions, which have promoted the economic development. We should build Tengchong as tourism city which focus on "washing lungs, moisturizing, meditation and elderly care", and make the place "a hometown of the Chinese mind". Meanwhile, increase advertisement and build the GuoShang Cemetery as the representative of the red tourism scenic spots, accelerate the realization of the main scenic spots WIFI full coverage services, excavate and develope more high-quality tourist attractions, such as "hot sea soup house". In addition, Baoshan needs to focus on hot-spring resort, elderly care, health care and other investment projects to promote economic and cultural development. With the help of Baoshan's overseas Chinese culture and the geographical advantages of China and Myanmar, we will energetically develop services such as logistics, finance and tourism, increase inter industry investment, improve infrastructure construction and social service construction.

4) Seize the policy opportunities, promote economic development

In the opportunities of "the Belt and Road" and Meng Chong India and Burma Economic Corridor construction, Baoshan [10], as a gateway to the South and Southeast Asia, should make full use of the unique geographical advantage and deepen the development strategy of "go out". Promote the development of water-land transshipment between China and Burma. Open up domestic and international routes for the two major airports in Tengchong and Baoshan, and strengthen economic cooperation on the Tengchong border. Furthermore, vigorously develope bio pharmaceutical processing industry, textile, clothing, cross-border logistics and other industries, explore the international market and introduce foreign funds. In addition, drive the Characteristic agricultural products processing industry out of the border and accelerate the development of the border tourism industry to form an industrial chain. Lastly, adjust the industrial structure, narrow the gap between regions and achieving stable economic development.

\section{REFERENCES}

[1] Li Ji Yun,Sun Liang Tao.An empirical analysis of industrial structure and economic growth in Yunnan[J]. Industrial Technology Economics,2005,24(8):90-115.

[2] Feng Mei Ling.An empirical study of industrial structure and economic growth in Hubei[D].Hubei University,2013.

[3] Liu Wei,Li Shao Rong.Industrial structure and economic growth[ J].China Industrial Economy,2002,(5):14-21.

[4] Feng Xin Lin,Ye Bo.Regression analysis of industrial structure to Jiangxi's economic growth[J].Economic Research,2011,11 : 34-36.

[5] Zhu Xiao Hua,Deng Bao Yi.An empirical analysis of the impact of China's industrial structure on economic growth[J].Enterprise Economy,2013,(7):132-136.

[6] Lu Jin,Hou Chuan Lu.Analysis of the relationship between industrial structure change and economic growth-An empirical study based on Qingdao[J].Journal of Qingdao Administration College, 2015,(4) : 1963.

[7] Zhang Li.Study on the relationship between regional industrial structure and economic growth--An example based on sichuan[D]. Wuhan University of Science and Technology,2015.

[8] Tang Gui Gang.Analysis of industrial structure and its influence on economic growth in Shandong Province[D].Beijing Forestry University,2016.

[9] Rymes k. Structural Change and Economic Growth: A Theoretical Essay on the Dynamics of the Wealth of Nations by L. Pasinetti[J]. Proceedings of SPIE - The International Society for Optical Engineering,2008,6879(2):717-723.

[10] Laitner J. Structural Change and Economic Growth[J]. Review of Economic Studies,2000,67(3):545-561. 